\title{
ANALISIS HADIS TENTANG AMAL BERKELANJUTAN DAN PENDIDIKAN SALAT BAGI ANAK
}

\author{
Zainal Abidin \\ STAIN Datokarama Palu, Jl. Diponegoro 23 Palu \\ e-mail: abidzainalabidin@gmail.com
}

\section{Abstract}

Islam asserts that whatever Muslims do in this world will give impacts to their life in the hereafter. However, not all good deeds that muslims have performed so far in this world will always give incessant rewards, particularly for the deceased, except for three things as stated in the Prophetic hadith: $s \square$ adaqah jâriyyah (charity), beneficial knowledge for others, and good descendants who always pray for them. These categories are still debated by some scholars. Therefore, this paper is intended to study this hadith in order to reveal its validity.

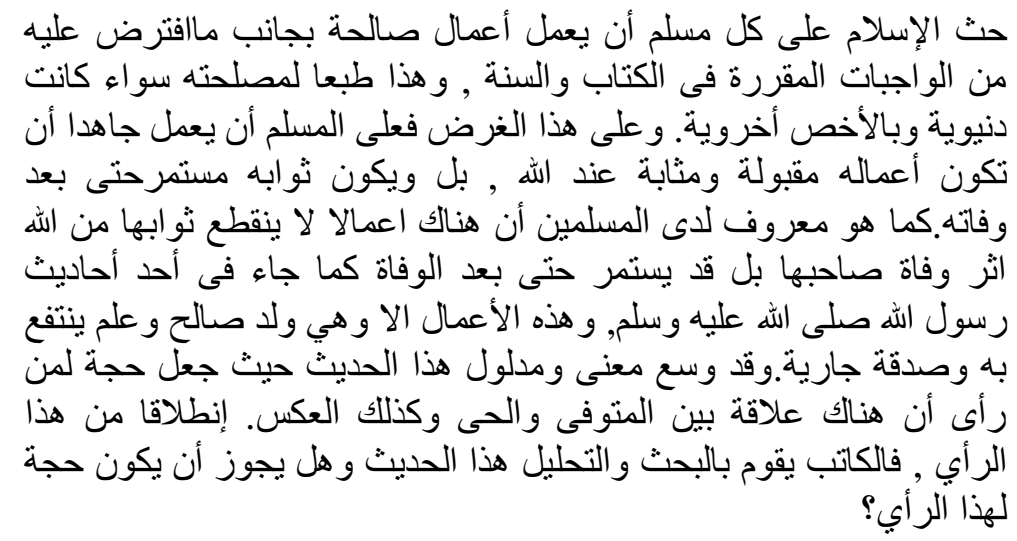

Kata Kunci: hadis, amal berkelanjutan, pendidikan salat, hujjah 


\section{PENDAHULUAN}

Sangat populer kita ketahui bahwa Alquran merupakan sumber pertama ajaran Islam. Namun demikian, teknik pelaksanaan ajaran Islam yang bersumber dari Alquran, seringkali hanya dapat ditemukan melalui penjelasan hadis-hadis nabi. Sebagai contoh, kewajiban menegakkan salat, kita temukan dalam Alquran, tetapi petunjuk pelaksanaannya secara lebih rinci hanya dapat diketahui melalui penjelasan hadis-hadis nabi. Demikian pula perintah melaksanakan puasa, membayarkan zakat, menunaikan ibadaha haji dan berbuat amal saleh, kita temukan dalam ayat-ayat Alquran, tetapi Alquran tidak menjelaskan amal-amal kebaikan bagaimanakah yang akan tetap memberikan pahala bagi yang melakukannya walaupun pelakunya telah meninggal dunia. Penjelasan mengenai hal ini hanya diketahui melalui hadis-hadis nabi.

Setiap pribadi muslim dianjurkan oleh agamanya untuk melakukan amal saleh, baik untuk kehidupan dunia, maupun bagi keselamatan akhirat. Untuk maksud tersebut, setiap muslim berupaya agar amalnya dapat diterima Allah swt. bahkan hingga wafat pun amalnya tersebut dapat berkelanjutan. Di dalam hadis nabi disebutkan bahwa ada tiga amal yang diterima akibatnya sampai seseorang telah wafat, yaitu (1) $s \square$ adaqah jâriyyah; (2) ilmu yang bermanfaat; dan (3). anak yang saleh yang ditinggalkannya, yang mendoakannya Pandangan ini didasarkan pada hadis nabi, bahkan tidak jarang hadis itu dikembangkan pengertiannya ke masalah ada tidaknya hubungan orang hidup dengan orang mati atau sebaliknya.

Untuk itulah, penulis merasa perlu melakukan penelitian hadis agar dapat diketahui, dapat atau tidaknya hadis tersebut dijadikan hujjah. Selain itu, penulis menganalisis hadis tentang perintah salat bagi anak sedini mungkin yang merupakan kewajiban orang tua, yang sekarang ini mulai terabaikan. Pembahasan hadis ini dimaksudkan agar dapat dijadikan sebagai pegangan bagi keluarga muslim, jika hadis tersebut layak dijadikan hujjah.

Ada lima kitab hadis yang menguraikan topik di atas, akan dianalisis dalam tulisan ini, yaitu Sahîh Muslim, Sunan al-Turmûdhî, Sunan al-Nasâ'̂े, Sunan Abî Dâwud dan Musnad Ahamad bin $H \square$ anbal, yang masing-masing memuat hadis tentang amal berkelanjutan dan pendidikan salat bagi anak. 


\section{TAKHR̂ิJ, I'TIBÂR, ANALISIS SANAD DAN MATN HADIS}

\section{Hadis Pertama}

Penulis menemukan data hadis dalam al-Mu'jam al-Mufahras li al-Fâz al-Hadîth al-Nabawî dengan lafal ولد, جرى, إنقطع, عمل, عمله إنه اذا مات ابن آدم إنقطع عمله, ولد صالح إلا من صدقه : dengan potongan hadis: yang terdapat pada kitab Sahîh Muslim bab XIV kitab Wisâyah, Abû Dâwud bab IV kitab Wisâyah, Al-Nasâ'î bab VIII kitab Wisâyah, AlTurmûdhî bab XXXVI kitab Ahkâm, Ahmad bin Hanbal juz II, bab II dan Ibn Mâjah bab II (Winsinck, 1995: 340, 311, 314).

Berdasarkan data tersebut, ditemukan matn hadis yang semakna karena ternyata lafal Ibn Âdam dalam hadis yang ditunjuk, tidak ditemukan kecuali al-Insân. Dengan demikian, hasil takhrîj al-hadîth pertama, yaitu: (1) Muslim dalam Sahîh Muslim, juz II h.14; (2) Abû Dâwud dalam Sunan Abî Dâwud juz III h. 117; 3). Ahmad bin Hanbal dalam Musnad Ahmad juz III h. 306; (4) Al-Nasâ'î dalam Sunan alNasâ'î juz V h. 251; dan (5) Al-Turmûdhî Sunan al-Turmûdhî h. 660.

Mengenai sanad-sanad hadis pertama melalui sanad yang mukharrij-nya al-Nasâ'̂̂ (objek pembahasan) yaitu: (1) al-Nasâ'̂̂, (2) 'Alî bin Hujrî, (3) Ismâ'îl bin Ja'far, (4) Al-'Alâ'i ibn 'Abd alRahmân, dan (6) Abû Hurayrah. Teks hadis sebagai berikut:

\section{Pertama, teks hadis dalam Sahîh Muslim}

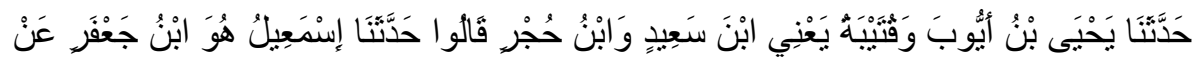

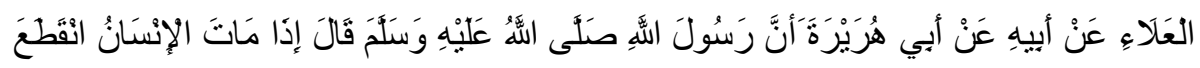

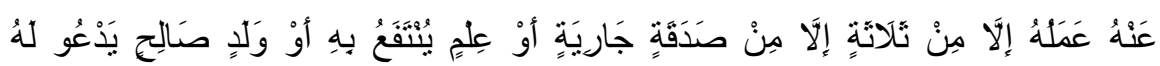

(Muslim,juz II, t.th.:14)

\section{Kedua, teks hadis dalam Sunan al-Turmûdhî}

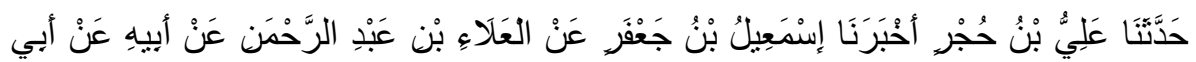

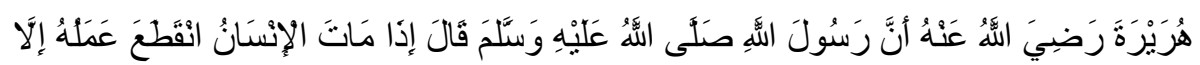

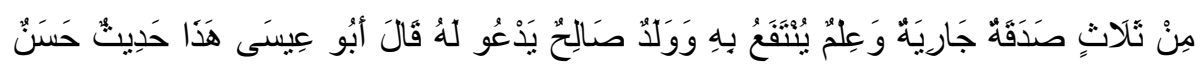
(Al-Turmûdhî, juz III, t.th.: 660) صَحِيحُ 
Jurnal Hunafa Vol. 5, No.2, Agustus 2008:241-256

\section{Ketiga, teks hadis dalam Sunan al-Nasâ'î}

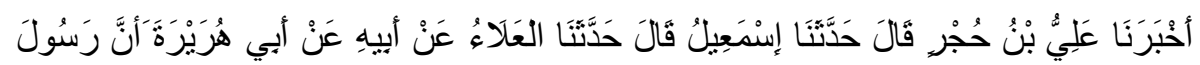

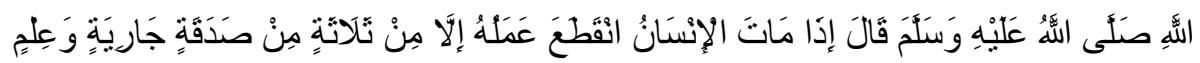

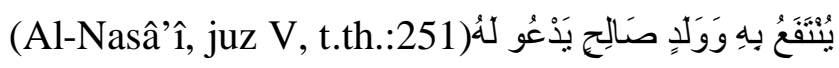

Keempat, teks hadis dalam Musnad Ahmad bin Hanbal

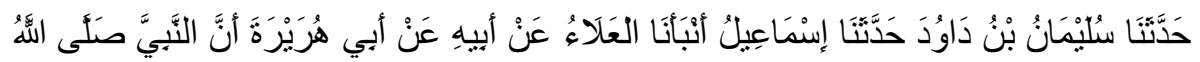

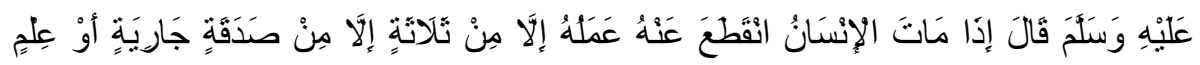

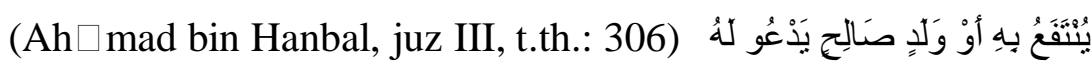

\section{Kelima, teks hadis dalam Sunan Abî Dâwud}

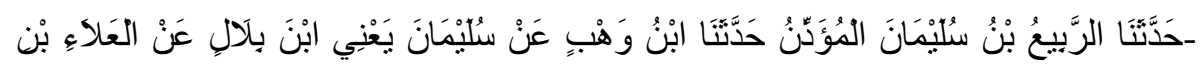

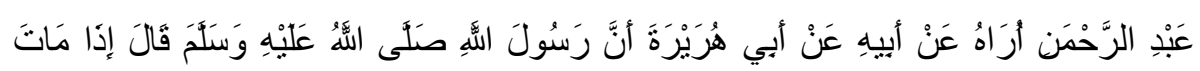

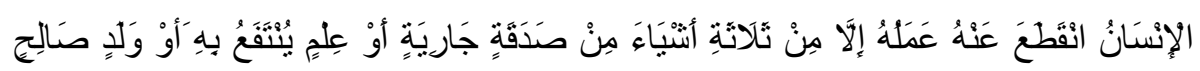

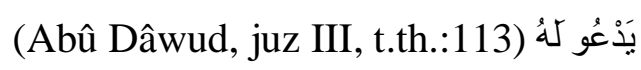

\section{Keenam, teks hadis dalam Sunan Ibn Mâjah}

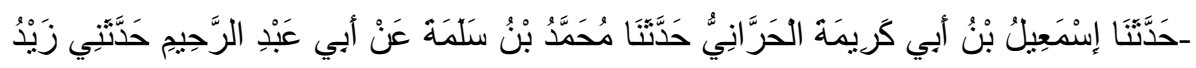

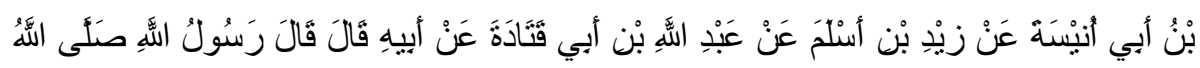

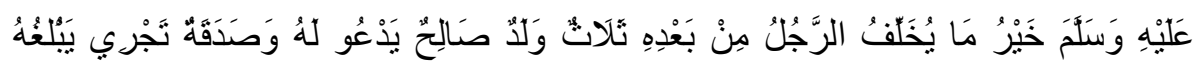

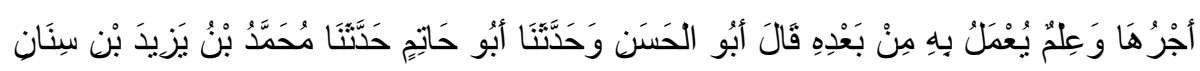

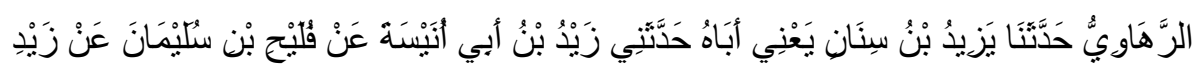

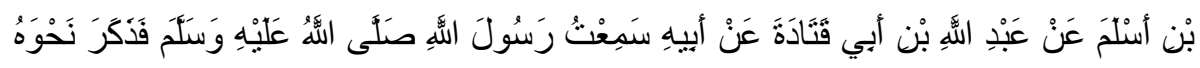

(Ibn Mâjah, juz I, t.th.: 33)

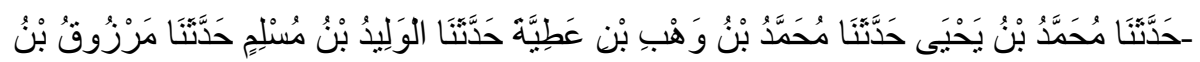

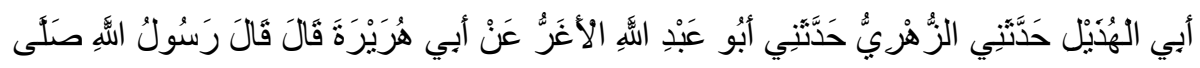

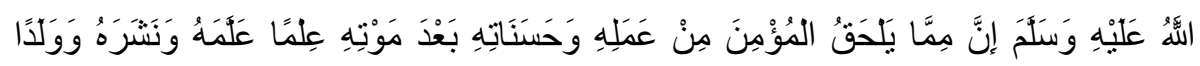




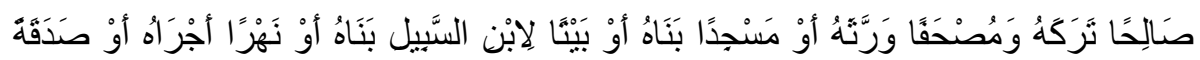

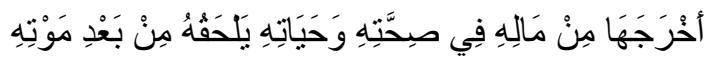

(Abû Dâwud, juz III, t.th.: 33)

Dengan demikian, apabila matn hadis pertama diteliti pada semua jalur periwayatan secara cermat, maka nampak pada matn hadis yang diriwayatkan oleh Ibn Mâjah terdapat perbedaan redaksi yaitu:

$$
\text { خير ما يخلَف الرجل من بعده ثلات .... }
$$

Untuk memberikan gambaran sanad hadis pertama, berikut ditampilkan skema seluruh sanad dan periwayatnya.

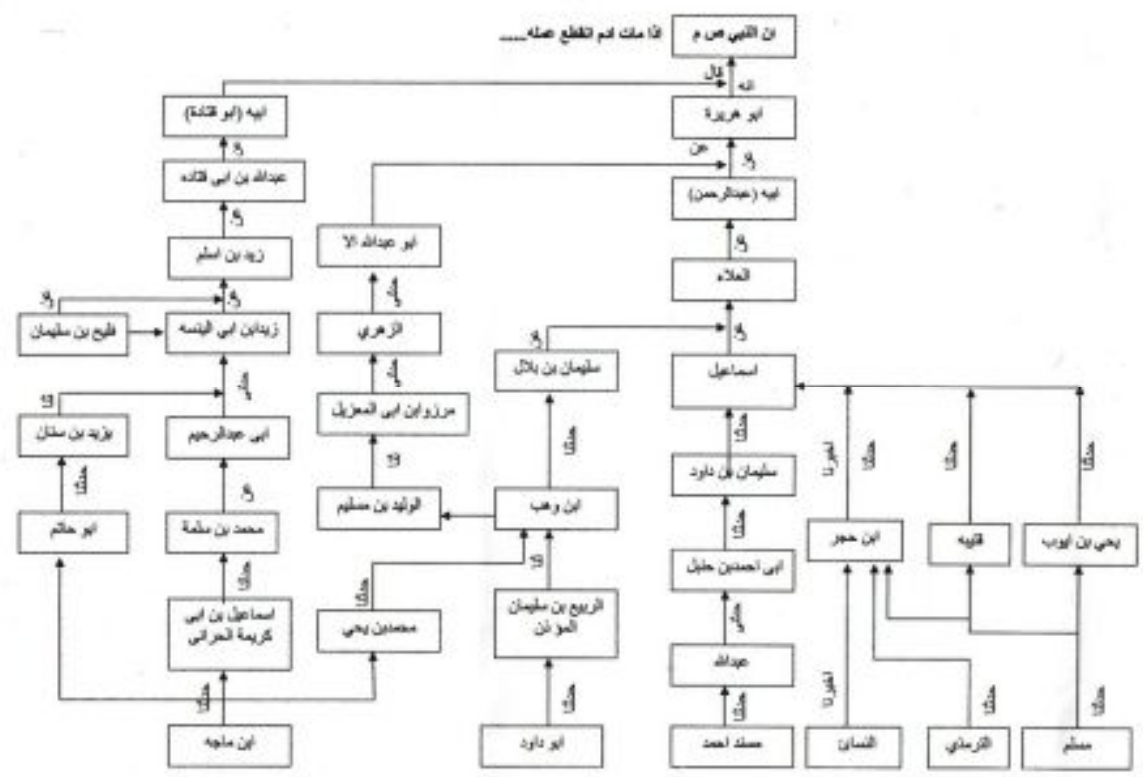

Memperhatikan skema di atas (hadis pertama) dapat diketahui bahwa periwayat yang berstatus shâhid yaitu Abû Qat $\square$ âdah. Untuk meneliti kualitas matn hadis, terlebih dahulu dikemukakan penilaian ulama hadis terhadap para sanad: 
Pertama, Al-Nasâ'î

Nama lengkapnya ialah Abû 'Abd al-Rahmân Ahmad bin Shu'ayb bin 'Alî bin Sannân bin Bahr al-Naghâ'̂̂. Ia lahir pada tahun 215 H., dan wafat di Palestina tahun 303 H. Gurunya adalah Qutaybah bin Sa'îd, Ishâq bin Râhawî, Hishâm bin 'Amr, 'Îsâ bin Hammad, $\mathrm{H} \square$ usayn bin Mansûr al-Salamî al-Naysabûrî, dll. Sedangkan muridnya adalah Abû Bashîr al-Daulâbî, Abû 'Alî al-Husayn alNaysabûrî, Hamzah bin Muh $\square$ ammad al-Kannânî, Abû al-Kâsim alTabrarî (Al-Nasâ'î, 1985:7-9).

Tanggapan terhadap beliau adalah sebagai berikut: (1) Abû 'Alî al-Naysabûrî menyebutnya: حافظ حرسان فى زمانهـ; (2) Manshûr al-Faqîh

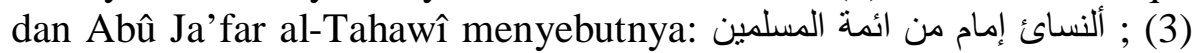
أبو عبد الرحمن مقدم على كل من يذكر بـهذ العلم من Al-Daruqutnî menyebutnya أهل عصره ; dan (4) Al-Shubkî mengatakan aku pernah bertanya kepada guruku Abû 'Abd Allâh al-Zahabî al-Hâfiz, mana yang lebih hâfiz, Imam Muslim daripada Al-Nasâ'î? Guruku menjawab Al-Nasâ'î (AlNasâ'î, 1985: 19). Dengan demikian, dapat disimpulkan bahwa AlNasâ'î adalah orang yang sangat hâfiz dan thiqah.

Kedua, 'Alî bin Hujrî (w.244H)

Nama lengkapnya ialah 'Alî bin Hujrî bin Ilyâs bin Muqâtil bin Muhâddishî bin Mashmûlî bin Khalîl al-Sa'di Abû al-Hasan alMarwazî, ia meriwayatkan hadis dari bapaknya, Ma'ruf al-Khayat Khâlif bin Khalîfah, 'Îsâ bin Yûnus, Ismâ'îl bin Ja'far, Ismâ'îl bin 'Âliyah, Jarîr bin Mubârak al-Darawarda dan seterusnya. Sedangkan yang menerima hadis darinya ialah Al-Bukhâri, Muslim, AlTurmûdhî, Al-Nasâ'î, Abû Amr, dan lain-lain. Muhammad bin 'Alî bin Hamzah al-Marwazî menilainya fâdilan hâfizan, Al-Nasâ'̂̂ menilainya thiqah ... hâfizan, Al-Khatîb menilainya sâdiqan ... hâfizan (Al-'Asqalânî, jilid III, 1968: 34)

Ketiga, Ismâ'̂̂l bin Ja'far

Nama lengkanpya ialah Ismâ'il bin Ja'far bin Abî Kathîr alAnsârî al-Zarq Maulâhum Abû Ishâq al-Qâri'. Beliau menerima hadis dari Abû Tuwâlah 'Abd Allâh bin Dînâr, Ja' far al-Shâdiq, Hamîd alTawil, Isrâ'il bin Yûnus, 'Amr bin 'Amr, al-'Alâ'i bin 'Abd alRahmân, Muhammad bin 'Amr, Ibn Ajlan, dan lain-lain. Sedangkan 
diterima oleh Hahya bin Yahyâ al-Naisabûrî Abû al-Rabî’ al- Sahranî, 'Alî bin Hujrî, Qutaybah bin Zabûr, dan lain-lain. Ah $\square \operatorname{mad,~Abû~}$ Zar'ah al-Nasâ'î, Ibn Mâ'in, Ibn Sa'îd menilainya thiqah. Ibn Kharazî menilainya shadûq, Ibn Khayzamah menilainya thiqah, Ma'mûl Qâlil al-Khatâ menilainya, shadûq (Al-'Asqalânî, jilid I, 1968: 34).

\section{Keempat, Al- 'Alâ’i}

Nama lengkapnya Al- 'Alâ'i bin 'Abd al-Rahmân bin Ya'qûb alHarq Abû Shublî al-Madanî Maulâ al-Harghah. Beliau meriwayatkan hadis dari bapaknya, Ibn 'Umar, Anas, Sa'îd bin Ka'ab bin Mâlik, dan lain-lain. Sedang hadisnya diriwayatkan oleh Ibn Jurayj, Ibn Ishâq, Muhammad bin Ajlan dan Ismâ'îl bin Ja'far bin 'Alî (Al- 'Asqalânî, jilid III, 1968: 38).

Kelima, 'Abd al-Rah $\square$ mân

Nama lengkapnya ialah 'Abd al-Rahmân bin Ya'qûb al-Jahnî al-Madanî Maula al-Harghat. Hadis diterima dari bapaknya, Abû Hurayrah, Abû Sa'îd, Ibn 'Abbâs, Ibn 'Umar dan lain-lain. Al- 'Alâ'i (anaknya), Sâlim Abû Nadar Muhammad bin Ibrâhîm al-Yatîmî, Muhammad bin Ajlân, Muhammad bin 'Umar adalah penerima hadis dari beliau. Kritikus hadis menilainya yakni Abû Khâtim mengatakan kalau hadis diterima lewat bapaknya atau melalui Musayyab bin Râfi' maka keduanya itu dekat, Al-Nasâ'î menilainya laysa bihi ba'sa, sedang Ibn Hibbân dan Al-Ajlî, menilainya thiqah. Bahkan ia bersahabat dengan Abû Hurayrah menurut Al-Madanî.

Keenam, Abû Hurayrah (w. 57 H./676 M)

Nama lengkapnya ialah Abû Hurayrah al-Dausî al-Yamanî, tatkala nabi berada di khaibar, beliau datang kepada nabi. Beliau masuk Islam saat bertemu nabi dan berbaiat kepadanya. Nama beliau setelah memeluk Islam adalah 'Abd Allâh 'Abd al-Rahmân yang sebelumnya 'Abd Shams. Beliau bergaul dengan nabi kurang lebih 4 'tahun dan hamper tiada waktu beliau berpisah dengan nabi kecuali saat tidur (Al-Juzrî, juz IV, t.th.: 320)

Beliau dalam penilaian ulama hadis, sangat terpuji karena kekuatan hafalannya seperti yang diungkap oleh Ibn 'Umar bin alKhattâb, Al-Shâfi'î dan Al-Bukhâri (Ensiklopedia Islam, jilid I, 1994: 
42-43). Dari penjelasan di atas, tampak masing-masing sanad, mulai dari sanad pertama sampai dengan sanad terakhir melalui jalur AlTurmûdhî adalah ittisâl dan semua periwayat yang ada semua dinilai thiqah kecuali Al-'Alâ'i. Ibn Mâ'in menilai bahwa hadisnya tidak dapat dijadikan hujjah. Namun tak ada ulama hadis yang menilainya da'îf. Sehingga sanad tersebut tidaklah mengandung illat dan shudhûdh karena sanad-nya ittishâl. Oleh karena itu, dapat disimpulkan bahwa sanad hadis ini sahîh, begitu pula dengan matnnya dikatakan dapat diterima (sahîh). Dengan alasan sebagaima menurut Syuhudi Ismail (1992: 64, 141), tidak bertentangan dengan petunjuk Alquran dan hadis yang lebih kuat; tidak bertentangan dengan logika yang sehat dan susunan pernyataan tidak bertentangan dengan ciri-ciri hadis nabi.

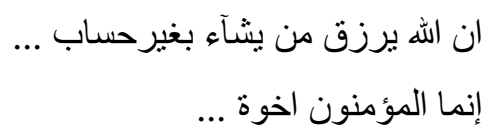

\section{Hadis Kedua}

Dalam al-Mu'jam ditelusuri lafal صلو dan ditemukan beberapa tempat hadis antara lain dengan potongan hadis:

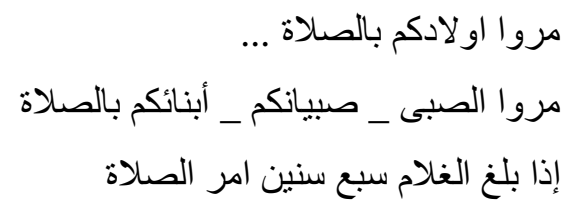

Dengan demikian diketahui terdapat 6 mukharrij hadis, yaitu: (1) Sahîh al-Bukhâri, kitab saum, hadis 136; (2) Sahîh Muslim, kitab saum bab 136; (3) Sunan Abî Dâwud, juz I, kitab salâh No. hadis 493 h. 133; (4) Musnad Ahmad bin Hanbal, juz V, No. 15338, h.232; (5) Sunan al-Turmûdhî, juz II, bab 182-183, h. 256; dan (6) Sunan alDârimî, juz I h. 333 (Winsick, juz III, 1955: 395). Namun deimikian, setelah diteliti, ternyata pada kitab Sahîh Muslim dan Sahîh al-Bukhâri dalam kitab saum tidak ditemukan hadisnya. Dengan demikian, hanya terdapat 4 mukharrij hadis yaitu: 


\section{Pertama, teks hadis dalam Sunan Abî Dâwud}

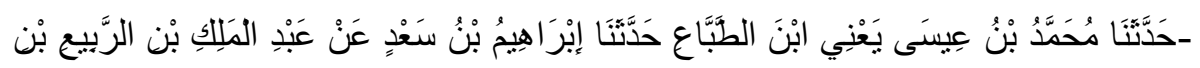

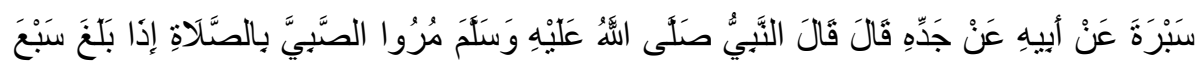

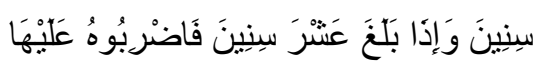

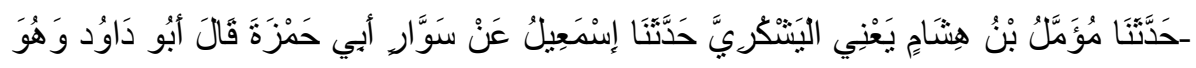

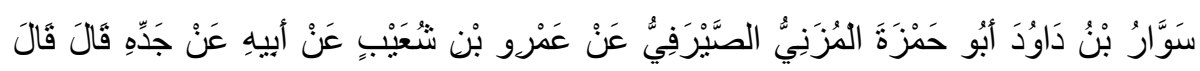

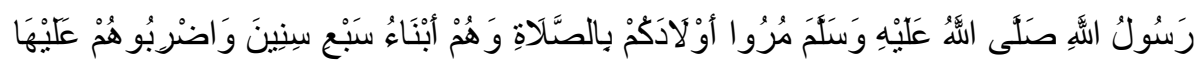

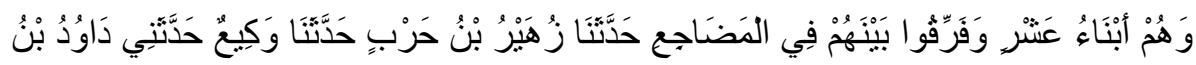

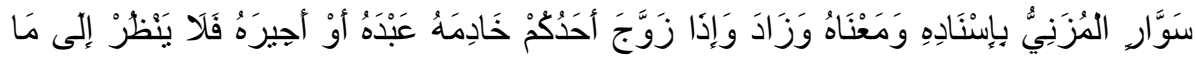

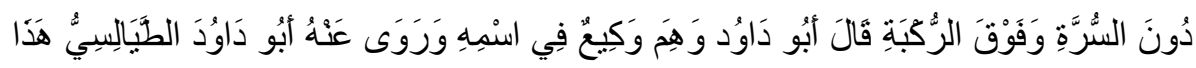

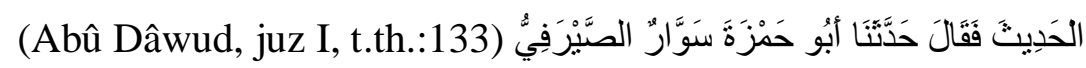

\section{Kedua, teks hadis dalam Musnad Ahmad bin H $\square$ anbal}

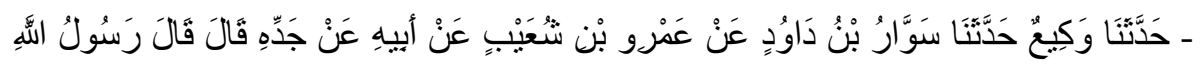

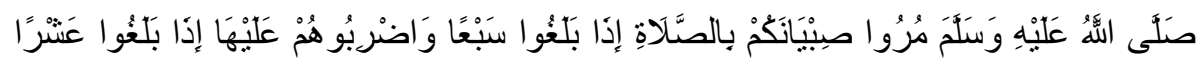

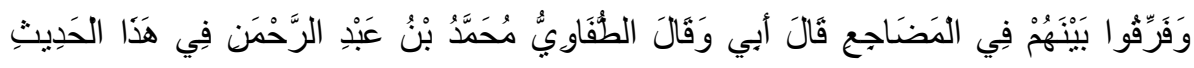

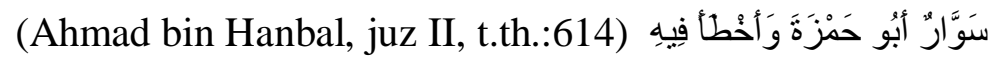

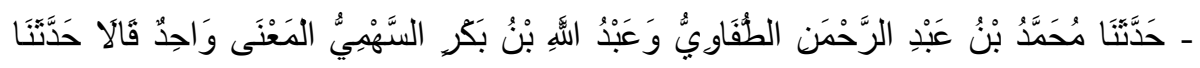

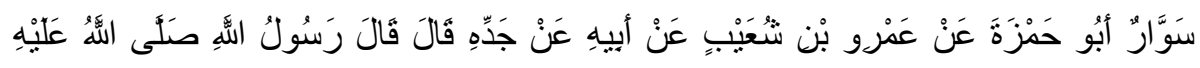

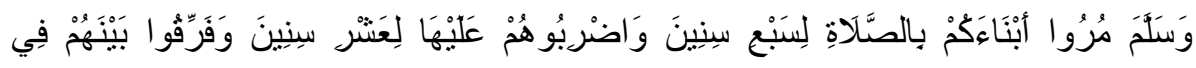




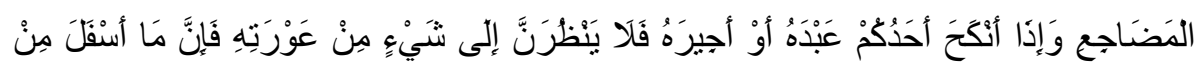

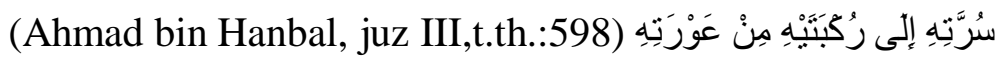

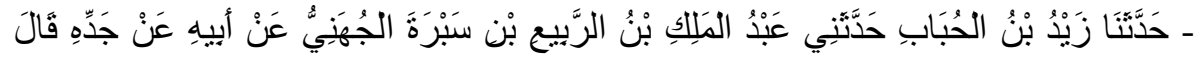

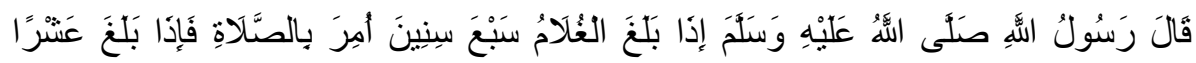
ضُربَ عَلْيْهَا (Ahmad bin Hanbal, juz IV, t.th.:232)

Ketiga, teks hadis dalam Sunan al-Turmûdhî

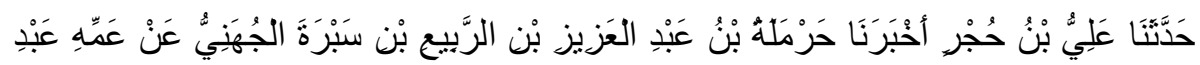

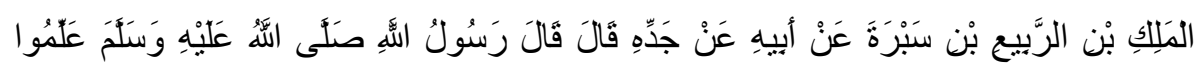

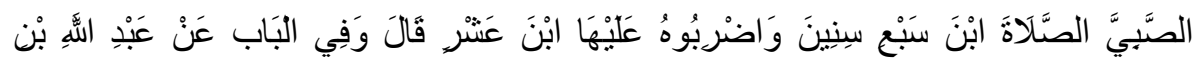

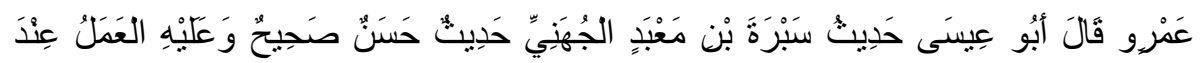

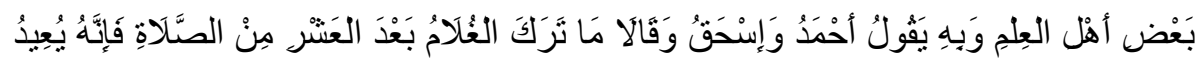

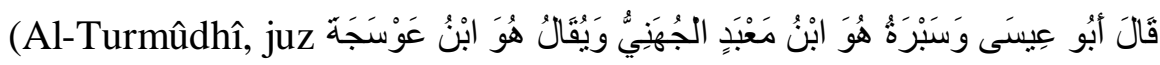
I, t.th:59)

\section{Keempat, teks hadis dalam Sunan al-Dârimî}

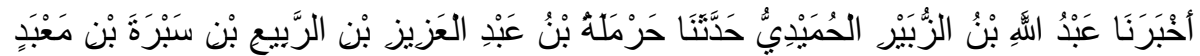

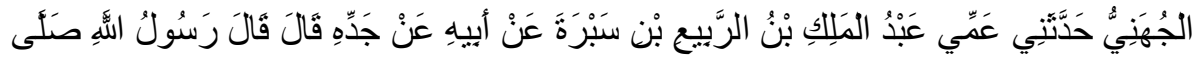

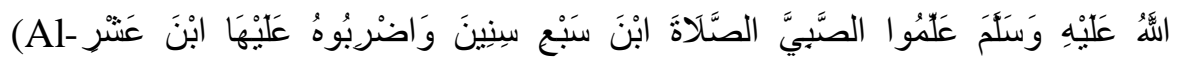
Dârimî, juz I, :333)

Dari teks hadis secara lengkap di atas terdapat perbedaan teks hadis tapi memiliki makna yang sama sehingga tidak mempengaruhi kualitas matn hadis dari satu sisi. Untuk lebih jelasnya pembahasan ini, penulis menampilkan skema sanad secara lengkap. 


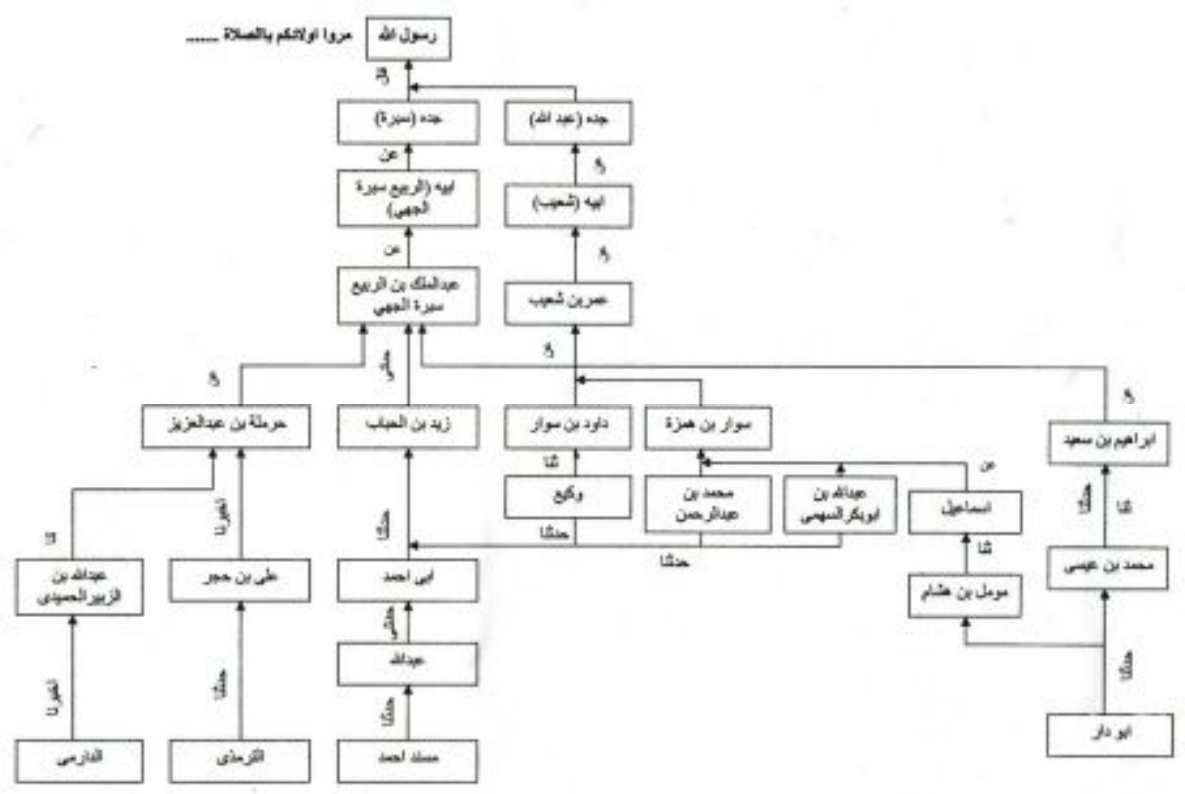

Dari skema tersebut, dapat diketahui bahwa keempat mukharrij hadis melalui dua jalur. Periwayat Abû Dâwud, Al-Turmûdhî dan AlDarimî memperoleh hadis dari jalur yang sama yaitu dari Sabrah, Rabî' dan 'Abd al-Mâlik. Setelah 'Abd al-Mâlik baru ada jalur tersendiri. Sementara itu, melalui periwayat $\mathrm{Ah} \square \operatorname{mad}$ bin Hanbal dan Abû Dâwud memperoleh hadis lewat jalur 'Abd Allâh, Shu'ayb, 'Amr dan Sawwâr. Setelah itu barulah masing-masing memiliki jalur tersendiri.

Periwayatan yang ditelusuri penulis, jalur Abû Dâwud khusus lewat jalur Sabrah. Sebab jalur 'Abd Allâh yang ternyata pada periwayat kedua dan ketiga terdapat penilaian kontroversial sehingga sulit diberikan penilaian terhadap kualitas sanad hadis tersebut (Al'Asqalânî, jilid I, 1968: 351-358). Jalur Sabrah selain mukharrij-nya Abû Dâwud juga Al-Dârimî, Al-Turmûdhî dan Ahmad bin Hanbal.

Untuk meneliti kualitas matn hadis kedua, ada baiknya dikemukakan penilaian terhadap para sanad.

Pertama, Abû Dâwud

Nama lengkapnya Sulaymân bin al-Ash'arî bin Ishâq bin Bâs $\square$ ir bin Syidad bin 'Amr bin Amran al-Azdî al-Sijistânî. Abû Dâwud menerima hadis dari sejumlah shaykh antara lain Ahmad bin 
$\mathrm{H} \square$ anbal, Muslim bin Ibrâhîm dan lain-lain. Sedangkan hadis beliau diterima oleh Abû 'Îsâ al-Turmûdhî, Abû 'Abd al-Rahmân al-Nasâ'î dan lain-lain (Enseklopedia Dunia Islam, jilid I, 1994: 40).

Kedua, Muhammad bin Îsâ

Nama lengkapnya Muhammad bin 'Îsâ bin Nâjihîn al-Baghdâdî Abû Ja'far ibn al-Tibhâ'i. Beliau menerima hadis dari Mâlik, Hammad bin Zayd, Ibn Abî Zi' bin, 'Abd al-Wâris bin Mu'îd, 'Abd al-Salam bin Hirbin, 'Abd Allâh bin Ja'far al-Makharâmî dan lain-lain. Muridmurid beliau, di antaranya Al-Bukhâri, Sha'laba, Abû Dâwud, AlTurmûdhî, Al-Nasâ'̂̂, Ibn Mâjah melalui 'Abd Allâh bin 'Abd alRahmân al-Sharûmî Muhammad bin Yahyâ, Sâhil bin Sâlih al-Zuhdî dan lain-lain.

Sementara penilaian ulama terhadap beliau antara lain menurut Bukhâri bahwa 'Alî dan Yahyâ serta 'Abd al-Rahmân, ketika mereka ditanya tentang Muhammad bin 'Îsâ, mereka mengatakan bahwa tiada yang lebih tahu hadis kecuali beliau. Abû Khâtim menyatakan bahwa menghafal hadis kurang lebih 40.000 hadis, Al-Nasâ'î menilainya thiqah. Ibn Hibbân menilainya thiqah dan dialah yang paling mengetahui hadis (Al-'Asqalânî, jilid IX, 1968: 392-394).

Ketiga, Ibrâhîm bin Sa'îd

Nama lengkapnya Ibrâhîm bin Sa'îd bin Ibrâhîm bin 'Abd alRahmân bin Auf al-Zuhrî Abû Ishâq al-Madanî. Hadis yang diterima beliau dari bapaknya Sâlih bin Kisân Sâlim, Muhammad bin Ishâq, Shu'bah, Yazîd bin al-Hâdi. Hadis dari beliau diriwayatkan oleh alLayth, Qaysh bin Rabî' (keduanya lebih tua), Yazîd bin al-Hâdi, Shu'bah (tergolong lebih tua daripadanya), Abû Dâwud, Yahyâ bin Yahyâ al-Naysabûrî dan lain-lain. Ahmad menilainya thiqah dan hadis-hadis dari beliau tidak mengalami perubahan. Abû Dâwud mengatakan, ia mendengar Ahmad bahwa Al-Wakî̀ apabila menerima hadis dari Ibrâhîm bin Sa'îd, cukup baginya dijadikan hujjah. Ibn Abî Maryam dari Ibn Mâ'in menilai thiqah, Ibn Abî Zi'bin menyatakan hadisnya kuat dan Bukhâri mengatakan bahwa Ibrâhîm berkata Ibrâhîm bin Sa'îd hafal 17.000 hadis (termasuk hadis hukum) (Al'Asqalânî, jilid I, 1968: 121-122). 
Keempat, 'Abd al-Mâlik bin Rabî' bin Sabrah

Ia menerima hadis hanya dari bapaknya, namun yang menerima hadis dari beliau adalah Harmalah 'Abd al-'Azîz, Ibrâhîm bin Sa'îd, Sa'îd bin Habbâb, Ya'qûb bin Ibrâhîm bin Sa'ad dan Al-Waqîdî. Abû Haytâmah menilainya $d a$ ' $f$, kalau ia menerima dari bapaknya. Pengarang Tahdhîb al-Tahdhîb menilai thiqah dan dalam Mizân alI'tidâl, ia menilainya sâduqûn inshâ Allâh, tetapi Ibn Mâ'in menilainya da'îf. Sedangkan Ibn Qattân menilai bahwa apabila hadisnya diriwayatkan oleh Muslim yang diambil dari 'Abd al-Mâlik, maka hadis itu tidak dapat dijadikan hujjah (Al-'Asqalânî, jilid VI, 1968: 393).

\section{Kelima, Al-Rabî' bin Sabrah}

Ia menerima hadis dari bapaknya sendiri, sedangkan hadis dari beliau diterima oleh 'Abd al-Mâlik, 'Abd al-'Azîz bin 'Umar bin 'Abd al-'Azîz, Al-Zuhrî dan lain-lain. Terdapat perbedaan penilaian ulama terhadapnya. Al-Ajlî, Al-Nasâ'î, dan Ibn Hibbân menilainya thiqah. Sedangkan Ibn Mâ'in menilainya $d a^{\prime} \hat{\imath} f$, jika hadis diterima melalui bapaknya. Adapun hubungan dengan bapaknya dapat dipastikan lagi sebab selain sebagai hubungan bapaknya dengan anak, juga keduanya saling mencantumkan sebagai guru dan murid dan thiqat al-tahammul yang digunakan adalah 'an (Al-'Asqalânî, jilid III, 1968: 244-245).

Keenam, Sabrah bin Ma'bad

Nama lengkapnya ialah Sabrah bin Ma'bad bin Ausâjah bin Harmalah bin Sabrah al-Juhârî, ia hanya meriwayatkan hadis kepada anaknya (Al-Rabî') hadis darinya diriwayatkan oleh Muslim tetapi Imâm al-Bukhârî menilainya mu'allaq (Al-'Asqalânî, jilid I, 1968: 221). Dari penjelasan di atas, dapat disimpulkan bahwa Sabrah bin Ma'bad sebagai periwayat I, Rabî' bin Sabrah dan 'Abd al-Mâlik bin Rabî' tampaknya penilaian terhadap Rabî' (periwayat II) dan 'Abd alMâlik (periwayat III) banyak menilai $d \square a$ ' $f$ apabila hadis tersebut diterima dari bapaknya. Dengan demikian sanad hadis tersebut mengandung illat shudhûdh. Oleh karena itu, dapat dikatakan bahwa kualitasnya $d a^{\prime} \hat{\imath} f$.

Namun demikian, dari segi matn hadis dipakai sebagai salah satu metode pendidikan bagi anak sedini mungkin agar mereka 
terbiasa melaksanakan salat, maka hadis tersebut dapat dijadikan hujjah atau ditanggapi positif. Tetapi bila dikaitkan dengan pribadi nabi yang sangat menyayangi anak-anak, lalu memerintahkan untuk memukulnya lantaran tidak menunaikan salat yang sesungguhnya belum wajib, adalah kurang dapat diterima untuk tidak mengatakan tidak logis. Secara akal sehat, kalau saja anak 10 tahun saja yang meninggalkan salat bagaimana dengan yang balig meninggalkan salat? Tentu lebih dari pada anak yang berumur 10 tahun.

\section{SYARAH HADIS}

Hadis pertama memberikan harapan dan dorongan agar umat Islam gemar melakukan amal kebajikan yang nilainya tetap dirasakan secara berkesinambungan walaupun yang bersangkutan telah wafat. Hadis pertama juga menjelaskan bahwa masih ada hubungan orang hidup dengan orang mati dalam arti orang hidup masih bisa memberikan bantuan yang sifatnya rohaniah kepada orang yang telah wafat. Walaupun yang meninggal tidak memiliki tiga hal seperti yang dinyatakan hadis, sebab yang dimaksudkan berdasarkan redaksi hadis, orang yang wafat tidak lagi menambah amalnya kecuali tiga hal, sehingga orang hidup masih dapat memberikan amalan kepada orang yang telah wafat. Hal ini didasarkan pada pemahaman persaudaraan sesama orang-orang yang beriman. Persaudaraan yang dimaksud bukan hanya waktu masih hidup, tetapi juga setelah mereka wafat.

Sementara hadis kedua merupakan salah satu metode pendidikan salat bagi anak-anak (7 - 10 tahun) bahkan sebelum usia itu juga bisa diterapkan karena ibadah salat akan dapat dilaksanakan secara berkelanjutan apabila sejak dini seorang anak telah terbiasamelakukannya. Salat secara material tidak dapat dilihat hasilnya yang mendorong orang melaksanakannya. Di sini, membiasakan anak melaksanakan salat sejak dini, menjadi sangat penting. Pukulan yang dimaksud adalah pukulan psikologis, bukan fisik apalagi yang menyakiti, atau dapat disimpulkan bergantung pada cara yang digunakan sehingga terjadi proses pembiasaan untuk melaksanakan salat bagi anak sedini mungkin. 


\section{PENUTUP}

Setelah penelitian hadis diuraikan dari berbagai hal, dapat disimpulkan bahwa hadis pertama dengan jalur Al-Nasâ'i dapat diketahui bahwa kualitas sanad-nya termasuk Sahîh karena tidak ditemukan illat dan shudhûdh. Sementara hadis kedua yang diteliti dari segi sanadnya, beberapa orang di antaranya diketahui memiliki "kekurangan" sehingga tidak memenuhi kriteria untuk disebut hadis yang dapat diterima (sahîh). Dengan kata lain hadis tersebut $d a$ '’̂f.

Bahwa jika salah satu dari tiga hal yang disebutkan hadis pertama ada pada seorang muslim, maka ia masih terus mendapat "nilainya" walaupun ia telah wafat. Bahkan sekaligus orang yang hidup pun masih bisa "berhubungan" dengan orang yang telah wafat dan dapat memberi "nilai" secara rohani.

Hadis kedua dari segi pendidikan (metodologi) dapat dipraktekkan dalam kehidupan keluarga untuk pembiasaan pada anak sedini mungkin untuk melakukan salat. Sedang pukulan terhadap anak yang dimaksud apabila ia meninggalkan salat adalah pukulan psikologis, yaitu pukulan yang dapat yang secara kejiwaan dapat memberikan kesadaran bagi anak bahwa kewajiban menunaikan salat adalah benar-benar kewajiban dari Allah swt. yang harus dilaksanakan sedini mungkin agar mereka terbiasa menjalankan kewajiban tersebut.

\section{DAFTAR PUSTAKA}

Abû Dâwud, Sulaymân bin al-Ash'arî bin Ishâq bin Bâsir bin Shidad bin 'Amr bin Amran al-Azdî al-Sijistânî. t.th. Sunan Abî Dâwud. Juz.I. Indonesia: Maktabah Dahlan.

al-'Asqalânî, Shihâb al-Dîn Abî al-Fadl Ahmad bin 'Alî bin Hajr. 1968. Tahdhîb al-Tahdhîb. Jilid I, III, IV, VI, VII, XI. Cet. I. Beirut: Dâr alSadr.

al-Athîr, Izz al-Dîn. t.th. Usud al-Ghâbah fì Ma'rifat al-Sahâbah. Juz IV. t.tp. Dâr al-Sha'b.

al-Bukhâri, Abû 'Abd Allâh Muhammad bin 'Uthmân al-Mughîrah. t.th. Sahîh Bukhâri. Juz.I. Mesir: Sharikah Misriyah.

al-Dârimî, 'Abd Allâh bin 'Abd al-Rahmân bin al-Fadl bin Burhân. t.th. Sunan al-Dârimî. Juz. I. Beirut: Dâr al-Kutb al-'Alamiyyah. 
al-Durûshî, 'Abd Allâh Muhammad. t.th. Musnad Ahmad bin Hanbal. Juz II, III dan V. Beirut :Dâr al-Fikr.

Ensiklopedi Dunia Islam. 1994. Jilid I. Jakarta: PT. Ichtiar Baru Van Hoeve. Ibn Mâjah, al-Hâfiz Abû 'Abd Allâh Muhammad bin Yazîd bin 'Abd Allâh al-Qazwînî. t.th. Sunan Ibn Mâjah. Juz. I. Beirut: Dâr al-Fikr.

Ismail, Syuhudi. 1992. Metodologi Penelitian Hadis. Cet. I. Jakarta: Bulan Bintang.

Muslim, Hajjaj al-Qushayrî al-Naishabûrî Imâm Abî al-Husayn. t.th. Sahîh Muslim. Juz I. Indonesia: Maktabah Dahlan.

al-Nasâ'î. t.th. Sunan al-Nasâ'î. Juz. V. Semarang: Toha Putra. . 1987. Al-Du'afầ' wa al-Matrûkîn. Cet. II. Beirut: Dâr al-Fikr.

al-Turmûdhî, Abû 'Îsâ bin Muhammad bin 'Îsâ bin Saurah bin Mûsâ bin alDahhâk. t.th. Sunan al-Turmûdhî. Juz. II dan III. Dâr al-Fikr.

Wensinck, J. 1965. Al-Mu'jam al-Mufahras li al-Fâz al-Hadîth al-Nabawî. Juz I, III, dan V. Leiden: t.p. 